Proceedings

\title{
Early Performance of Mortars Prepared with Binary and Ternary Binders Exposed to a Real Exposure Class XC4 Mediterranean Climate Environment ${ }^{\dagger}$
}

\author{
Javier Ibáñez-Gosálbez ${ }^{1, *}$, Teresa Real-Herraiz ${ }^{2}$ and José Marcos Ortega ${ }^{1}$ \\ 1 Departamento de Ingeniería Civil, Universidad de Alicante, Ap. Correos 99, 03080 Alacant/Alicante, Spain; \\ jm.ortega@ua.es \\ 2 Instituto de Matemática Multidisciplinar, Universidad Politécnica de Valencia, Camino de Vera s/n, 46022 \\ Valencia, Spain; tereaher@upv.es \\ * Correspondence: javier.ibanez@ua.es; Tel.: +34-96-5903-400 \\ † Presented at 1st International Electronic Conference on Applied Sciences, 10-30 November 2020; Available \\ online: https://asec2020.sciforum.net/.
}

Published: 10 November 2020

\begin{abstract}
At present, the reduction of $\mathrm{CO}_{2}$ emissions due to the cement manufacture is an important field of study. In this line, the production of commercial cements consisting of binary binders is relatively common. However, the manufacture of cements made with ternary binders is still very low, at least in Spain. In this work, it has been studied the short-term effects of the exposure to a real in-situ environment in microstructure and properties of different mortars. The in-situ condition consisted of exposing the samples to a Mediterranean climate environment in an inland location sited in Alicante province (Spain). This location would accomplish the specifications of exposure class XC4 defined by Eurocode 2. Reference mortars were prepared with ordinary Portland cement without additions. A binary binder was also studied, incorporating 30\% limestone, as well as two ternary binders, with addition 15\% limestone and $15 \%$ fly ash, and $15 \%$ limestone and $15 \%$ ground granulated blast furnace slag, respectively. The microstructure has been analyzed using mercury intrusion porosimetry. Absorption after immersion and compressive strength have also been studied. According to the results obtained, mortars with ternary binders showed a good behavior in the short-term compared to reference mortars.
\end{abstract}

Keywords: ternary binders; ground granulated blast furnace slag; fly ash; limestone; sustainability; microstructure; properties; Mediterranean climate environment; real condition exposure

\section{Introduction}

Nowadays, the development of strategies for reducing the $\mathrm{CO}_{2}$ emissions due to the cement manufacture is an important field of study. One of the ways of lessening those emissions is replacing clinker by additions [1]. In this line, the production of commercial cements consisting of binary binders in which are incorporated additions such as ground granulated blast-furnace slag, fly ash and limestone is relatively common. However, the manufacture of commercial cements made with ternary binders is still very low, at least in Spain. In this ternary binders, clinker is partially replaced by two additions, and they could also produce a good behavior of cement-based materials [2], due to the synergetic effect of both additions, with the added value of still being good solution for contributing to sustainability of cement industry. On the other hand, real structures are usually exposed to environments which differ with the laboratory conditions under the materials are generally studied. These different conditions of real environments can affect the development of 
microstructure and service properties of cement-based materials [3,4], especially if they are made using binary or ternary binders.

Therefore, the objective of this research to study the short-term effects (28 hardening days) of the exposure to real in-situ inland Mediterranean climate environment in the microstructure and service properties of mortars prepared with different binders, which incorporate limestone, fly ash and ground granulated blast furnace slag.

\section{Materials and Methods}

\subsection{Materials and Sample Preparation}

The tests were performed on mortars, which were prepared with different binders. First of all, reference mortars were made with ordinary Portland cement without additions, CEM I $42.5 \mathrm{R}$ (Spanish and European standard UNE-EN 197-1 [5]), and they were named as REF in the presentation of the results. In addition to this, a binary binder was studied, incorporating $30 \%$ limestone as a replacement of the abovementioned cement CEM I 42.5 R, and it was designed as L in the results and discussion section. Finally, mortars prepared with two ternary binders were also analyzed. The first one, designated as $\mathrm{SL}$, incorporated $15 \%$ ground granulated blast furnace slag and $15 \%$ limestone additions, replacing cement CEM I 42.5 R. The other one was named as VL and the cement CEM I $42.5 \mathrm{R}$ was replaced by $15 \%$ fly ash and $15 \%$ limestone additions. The specimens of the four binders studied were prepared with a water to cement ratio 0.5. Fine aggregate was used according to the standard UNE-EN 196-1 [6] and the aggregate to cement ratio was 3:1 for all the mortars.

Two different types of specimens were prepared. On one hand cylindrical specimens with dimensions $5 \mathrm{~cm}$ diameter and $6 \mathrm{~cm}$ height. On the other hand, prismatic samples with dimensions 4 $\mathrm{cm} \times 4 \mathrm{~cm} \times 16 \mathrm{~cm}$ were also made. Along their first $24 \mathrm{~h}$, all specimens were kept in $95 \% \mathrm{RH}$ chamber and $20^{\circ} \mathrm{C}$. After that time, they were de-moulded and they were cured under that optimum condition up to 7 hardening days, when they were moved to the real in-situ environment. Several experimental works have shown [4] the importance of curing in the development of service properties of cement-based materials exposed to non-optimum environments. For this reason, in this work it has been chosen a curing period of 7 days.

\subsection{Environmental Exposure Condition}

The real in-situ condition consisted of exposing the samples to Mediterranean climate environment in an inland location sited in Orxeta town ( $38^{\circ} 33^{\prime} 47^{\prime \prime} \mathrm{N}, 0^{\circ} 15^{\prime} 43^{\prime \prime} \mathrm{W}, 177$ m.a.s.l.), which belongs to Alicante province (Spain). This exposure station is not too far away from the coast (10 km approximately). The samples were placed in the roof of a detached house and they were not protected from the weather conditions. This location would accomplish the specifications of exposure class XC4 (corrosion induced by carbonation, cyclic wet and dry) defined by the Eurocode 2 [7].

The exposure period studied in this work started at the age of 7 hardening days (when finished the curing time of the samples) and finished at 28 hardening days, covering part of the months of February and March, which corresponds with the final of the winter season. The evolution of temperature and relative humidity $(\mathrm{RH})$ registered in the exposure station during the studied time interval is shown in Figure $1 \mathrm{a}, \mathrm{b}$ respectively. Regarding the temperature, this parameter ranged between $9{ }^{\circ} \mathrm{C}$ and $23{ }^{\circ} \mathrm{C}$, and $\mathrm{RH}$ varied in the interval from $22 \%$ to $99 \%$ along the exposure time period. In relation to the rainfall, it rained in 9 days of the exposure period and $19 \mathrm{~mm}$ of total precipitation was registered in the site. Finally, the maximum wind speed showed high changeability, reaching a maximum peak of $70 \mathrm{~km} / \mathrm{h}$. 


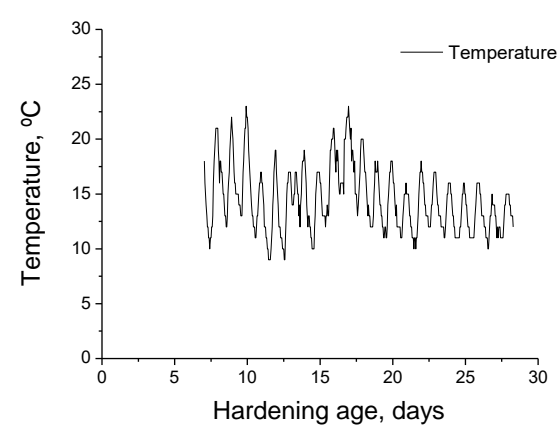

(a)

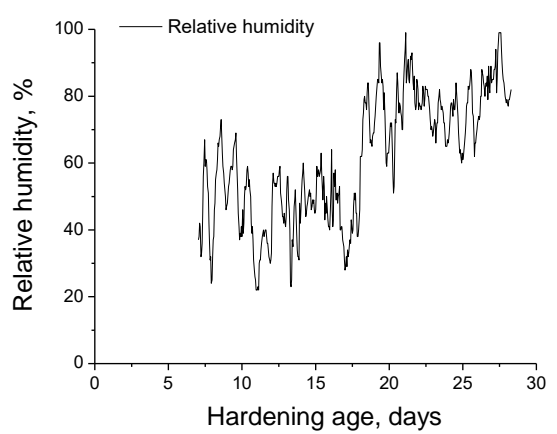

(b)

Figure 1. (a) Temperature registered in the exposure station along the time period studied. (b) Relative humidity registered in the exposure station along the time period studied.

\subsection{Experimental Tecniques}

The microstructure of the mortars was characterized using mercury intrusion porosimetry. This technique was performed using a Poremaster-60 GT porosimeter manufactured by Quantachrome Instruments (Boynton Beach, FL, USA). Previously to the test, the specimens were dried in an oven at $50{ }^{\circ} \mathrm{C}$ for $48 \mathrm{~h}$. The results analyzed in this research were total porosity and pore size distribution at 28 hardening days. Two measurements were made on each type of mortar and the samples tested were pieces taken from cylinders with dimensions $5 \mathrm{~cm}$ diameter and $6 \mathrm{~cm}$ height.

Regarding the service properties of the mortars, the absorption after immersion and the compressive strength were determined at 28 hardening days. The absorption after immersion was determined according to the ASTM Standard C642-06 [8] and six pieces taken from cylinders with dimensions $5 \mathrm{~cm}$ diameter and $6 \mathrm{~cm}$ height were tested for each kind of mortar studied. The compressive strength was obtained in prismatic samples with dimensions $4 \mathrm{~cm} \times 4 \mathrm{~cm} \times 16 \mathrm{~cm}$ according the Spanish and European standard UNE-EN 1015-11 [9]. Three prismatic samples were tested at the studied age for each one of the analyzed binders.

\section{Results and Discussion}

\subsection{Microstructure Characterisation}

In relation to the results obtained using mercury intrusion porosimetry technique, the total porosities noted for the analyzed mortars can be observed in Figure 2a. The lowest value of this parameter at 28 days has been observed for reference mortars without additions (REF samples), however the specimens with incorporation of limestone and ground granulated blast furnace slag (SL mortars) showed a slightly higher total porosity but very similar to REF ones. On the other hand, the largest total porosities have been noted for mortars with only limestone addition (L specimens), followed by those samples which incorporate both limestone and fly ash additions (VL mortars).

The pore size distributions of the mortars studied are depicted in Figure $2 \mathrm{~b}$. The more refined pore network, with higher percentage of pores with smaller diameters, has been observed for REF mortars. The samples prepared with ternary binders showed similar pore size distributions, being slightly more refined for SL mortars in comparison with VL ones. The L samples had the less refined pore network, highlighting their low proportion of pores with sizes lower than $100 \mathrm{~nm}$.

The highest total porosity and the lower pore refinement observed for $\mathrm{L}$ mortars could be related with the fact that limestone is not an active addition, so its presence only has a filler effect and it does not react for producing new solid fraction, which would progressive reduce the pores size and consequently the total porosity. In the case of REF mortars, the higher percentage of clinker, compared to L specimens, available for the development of hydration reactions [10] would make possible a greater solids formation during the 28 hardening days period studied, which would entail a higher pore refinement and lower total porosity, as has been observed. 
With respect to ternary binders, the similar total porosity observed for SL mortars compared to REF ones could be due to the effect of the slag as active addition and its hydration reactions [11], giving as products new solid fraction, reducing the porosity. This would also explain the lower porosities of SL mortars respect to L ones. Nevertheless, regarding the pore size distribution, SL specimens showed lower pore refinement compared to REF mortars, with a slight smaller percentage of pores with diameters below $100 \mathrm{~nm}$, despite of showing similar total porosities. This could be related to the relative low environmental temperatures in the real in-situ location during the exposure time period studied, which ranged between $9{ }^{\circ} \mathrm{C}$ and $23^{\circ} \mathrm{C}$ as has been noted in Section 2.2. Both clinker and slag hydration reactions are influenced by temperature [10,12], although this influence is more noticeable for slag [13]. Therefore, in an environment with temperatures lower than the optimum one, the hydration reactions of slag would significantly slow down, which would affect to the consequent formation of solids and microstructure development, as revealed the pore size distribution of SL mortars.

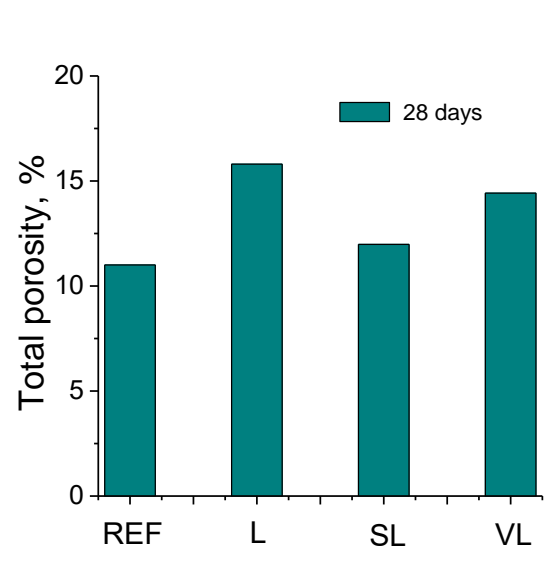

(a)

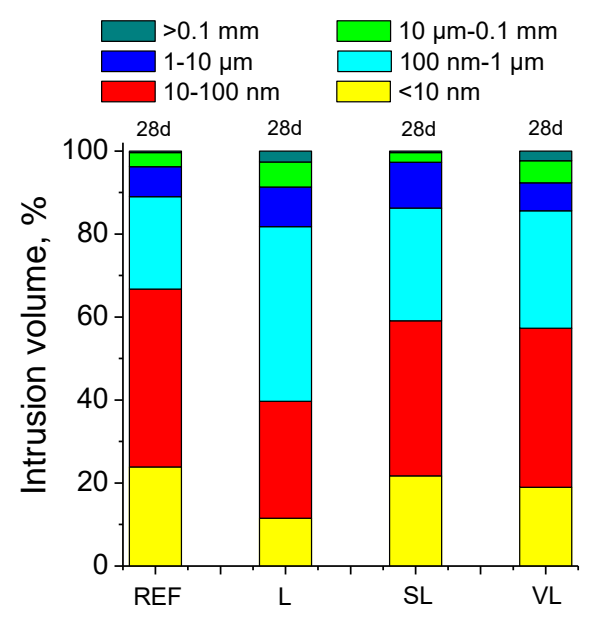

(b)

Figure 2. (a) Total porosity results obtained for the studied mortars; (b) Pore size distributions (in percentage) for the different types of mortars analyzed.

In relation to the other ternary binder analyzed in this work, the higher total porosity and less pore refinement noted for VL mortars compared to those obtained for REF and SL specimens could be due to the effect of fly ash addition. The pozzolanic reactions of fly ash need the presence of portlandite to be developed [14]. At 28 hardening days and in an environment with low temperature, which would make slower the clinker hydration reactions [10], it could be expected that not too much amount of portlandite would be available yet for the fly ash pozzolanic reactions, so their effect in the microstructure would not be very notable at that age, as suggest the total porosity results. In addition to this, the pozzolanic reactions of fly ash could be in turn slowed down by the relatively low environmental temperature in the exposure site $[13,15]$, probably making more difficult the formation of new solids as products of this reactions. This could also contribute to explain the differences between the microstructure results of REF and VL specimens. However, it is expected that the beneficial effects of the fly ash addition would be observed as larger exposure ages, when a greater development of pozzolanic reaction will be produced.

On the other hand, comparing both ternary binders studied, the SL mortars showed lower total porosities and slight higher pore refinement than VL specimens. This could be due to the different behaviour of both active additions. As has been previously explained, the hydration of slag is produced since the setting, when this addition get in touch with water, while fly ash needs the presence of portlandite for starting the pozzolanic reactions [14]. This delay between hydration and pozzolanic reactions, depending on the addition, with the already described environmental temperature effects on them, would explain the different behaviour in the very short-term of both ternary binders regarding the pore network. Lastly, as general comment for all the mortars studied, 
the rainfall in several days of the exposure time period studied could have had a beneficial effect in the microstructure development.

\subsection{Service Properties}

The results of absorption after immersion are shown in Figure 3a. Water is one the most important ways for ingress of aggressive substances in cement-based materials, so the study of this parameter is relevant. It has been noted scarce differences between the different binders analyzed. The highest value of this parameter has been observed for L mortars, which is accordance with the highest total porosity also noted for them. The lowest absorption corresponded to REF specimens, being again in accordance with their lower porosity. Finally, for ternary binders, this parameter was slightly higher than that observed for REF samples. In view of the results of absorption after immersion, it is interesting to emphasize that the behavior of binders with additions did not differ too much compared to reference mortar at 28 hardening days.

The compressive strength for each one of the mortars studied can be observed in Figure $3 \mathrm{~b}$. The largest strength corresponded to REF mortars and the smallest one was shown for L ones. The mortars prepared using ternary binders had a very similar compressive strength, lower than REF samples. These results are overall in keeping with mercury intrusion porosimetry ones, already discussed, especially with the pore size distributions, showing higher compressive strengths the specimens with a more refined microstructure.

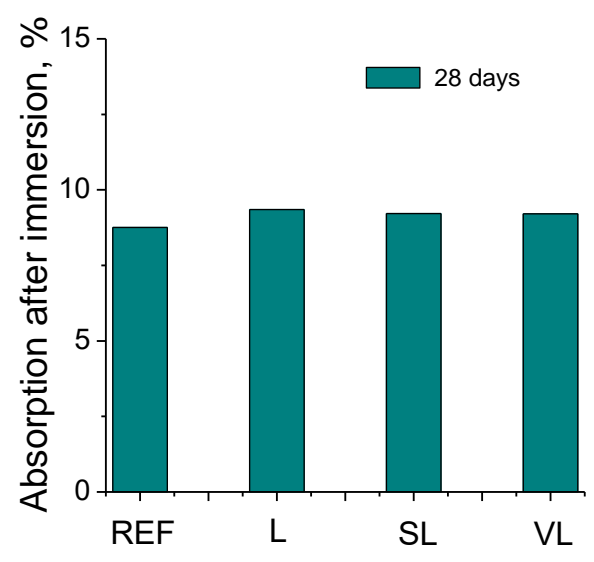

(a)

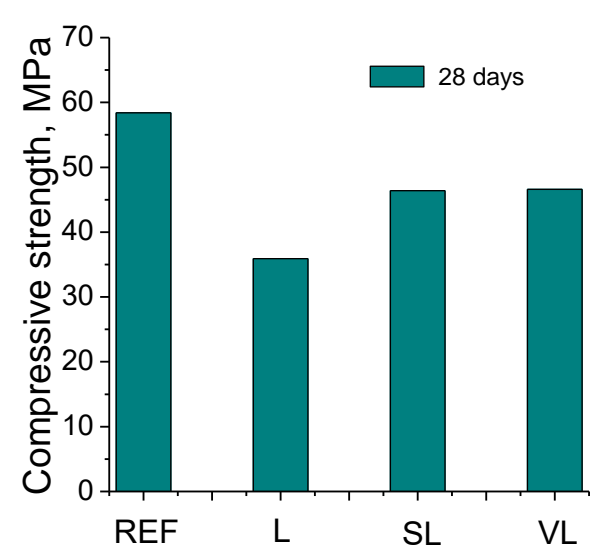

(b)

Figure 3. (a) Results of absorption after immersion for the studied binders; (b) Compressive strength results noted for analyzed mortars.

\section{Conclusions}

The main conclusions that can be drawn from the results previously discussed can be summarized as follows:

- The greater total porosity, the less pore refinement, the higher absorption after immersion and the lower compressive strength have been observed for mortars with the only addition of limestone, compared to the rest of binders studied. This could be due to the fact that limestone is not an active addition.

- The total porosity of mortars made with ternary binder which incorporated slag and limestone showed similar total porosity to reference mortars, although their microstructure was slightly less refined. This could be related to a slower development of the slag hydration due to relatively low temperatures in the exposure site along the time period studied.

- The mortars prepared using the ternary binder with the addition of fly ash and limestone showed higher total porosity and less pore refinement than reference ones. This could be explained in relation to the influence of fly ash, especially with the development of pozzolanic 
reactions of this addition, and its delay respect to clinker and slag hydration. The low environmental temperatures had also an influence in the development of the microstructure of mortars with fly ash.

- Regarding the absorption after immersion, the behavior of binders with additions did not differ too much compared to reference mortar at 28 hardening days.

- The compressive strength of mortars prepared with the binary and ternary binders studied were lower than that noted for reference specimens. The results of compressive strength were overall in keeping with the pore size distributions, showing higher compressive strengths the specimens with a more refined microstructure.

Author Contributions: Conceptualization, J.M.O. and T.R.-H.; methodology, J.M.O. and T.R.-H.; investigation, J.I.-G. and J.M.O.; data curation, J.I.-G., T.R.-H. and J.M.O.; writing-original draft preparation, J.I.-G.; writing-review and editing, J.M.O.; supervision, T.R.-H. and J.M.O.; The results included in this paper have been obtained in the PhD thesis carried out by J.I.-G. at University of Alicante (Spain), under the supervision of J.M.O. and T.R.-H. All authors have read and agreed to the published version of the manuscript.

Funding: This research received no external funding.

Acknowledgments: The authors wish to thank Cementos Portland Valderrivas S.A. for providing the cement CEM I 42.5 R and the limestone, fly ash and ground granulated blast furnace slag used in this study.

Conflicts of Interest: The authors declare no conflict of interest.

\section{References}

1. Letelier, V.; Tarela, E.; Osses, R.; Cárdenas, J.P.; Moriconi, G. Mechanical properties of concrete with recycled aggregates and waste glass. Struct. Concr. 2017, 18, 40-53, doi:10.1002/suco.201500143.

2. Cordeiro, G.C.; Toledo Filho, R.D.; Tavares, L.M.; Fairbairn, E.M.R. Experimental characterization of binary and ternary blended-cement concretes containing ultrafine residual rice husk and sugar cane bagasse ashes. Constr. Build. Mater. 2012, 29, 641-646, doi:10.1016/j.conbuildmat.2011.08.095.

3. Moffatt, E.G.; Thomas, M.D.A.; Fahim, A. Performance of high-volume fly ash concrete in marine environment. Cem. Concr. Res. 2017, 102, 127-135, doi:10.1016/j.cemconres.2017.09.008.

4. Thomas, M.D.A.; Scott, A.; Bremner, T.; Bilodeau, A.; Day, D. Performance of slag concrete in marine environment. ACI Mater. J. 2008, 105, 628-634.

5. AENOR UNE-EN 197-1:2011. Composición, Especificaciones y Criterios de Conformidad de los Cementos Comunes; 2000; Volume 30.

6. AENOR UNE-EN 196-1:2005. Métodos de Ensayo de Cementos. Parte 1: Determinación de Resistencias Mecánicas; 2005.

7. European Committee for Standardization. EN 1992-1-1 Eurocode 2: Design of Concrete Structures - Part 1-1: General Rules and Rules for Buildings; CEN, Ed.; CEN: Brussels, Belgium, 2004.

8. ASTM ASTM C642-06 Standard Test Method for Density, Absorption, and Voids in Hardened Concrete; 2006; Volume 3.

9. AENOR UNE-EN 1015-11:1999. Métodos de Ensayo de los Morteros para Albañilería. Parte 11: Determinación de la Resistencia a Flexión y a Compresión del Mortero Endurecido; 1999; Volume 16.

10. Escalante-García, J.I.; Sharp, J.H. Effect of temperature on the hydration of the main clinker phases in Portland cements: Part I, neat cements. Cem. Concr. Res. 1998, 28, 1245-1257.

11. Bijen, J. Benefits of slag and fly ash. Constr. Build. Mater. 1996, 10, 309-314, doi:10.1016/0950-0618(95)00014-3.

12. Geiseler, J.; Kollo, H.; Lang, E. Influence of blast furnace cements on durability of concrete structures. ACI Mater. J. 1995, 92, 252-257.

13. Escalante-García, J.I.; Sharp, J.H. Effect of temperature on the hydration of the main clinker phasesin Portland cements: Part II, blended cements. Cem. Concr. Res. 1998, 28, 1259-1274.

14. Wang, A.; Zhang, C.; Sun, W. Fly ash effects. Cem. Concr. Res. 2004, 34, 2057-2060, doi:10.1016/j.cemconres.2003.03.001.

15. Ortega, J.M.; Sánchez, I.; Climent, M.A. Impedance spectroscopy study of the effect of environmental conditions on the microstructure development of sustainable fly ash cement mortars. Materials 2017, 10, doi:10.3390/ma10101130. 
Publisher's Note: MDPI stays neutral with regard to jurisdictional claims in published maps and institutional affiliations.

() 2020 by the authors. Submitted for possible open access publication under the terms and conditions of the Creative Commons Attribution (CC BY) license (http://creativecommons.org/licenses/by/4.0/). 